\title{
A Study on Sustainability of Unregistered Agricultural Holdings in Bulgaria
}

\section{"Dr. HrabrinBachev, Professor}

Institute of Agricultural Economics, 125 “Tzarigradskoshose” Blvd, Blok 1, 1113 Sofia, Bulgaria. E-mail: hbachev@yahoo.com.

"Corresponding author: Dr. HrabrinBachev, Professor, Institute of Agricultural Economics, 125 "Tzarigradskoshose" Blvd, Blok 1, 1113 Sofia, Bulgaria. E-mail: hbachev@yahoo.com.

Citation: Bachev H (2017)A Study on Sustainability of Unregistered Agricultural Holdings in Bulgaria. J AgrAgri Aspect 2017: JAAA-115.

Received Date: 08 February, 2017; Accepted Date: 15 March, 2017; Published Date: 22 March, 2017

\begin{abstract}
The issue of adequate assessment of diverse aspects of sustainability of agricultural holdings is among the most topical academic and practical problems. In Bulgaria there have been no comprehensive studies on socio-economic and environmental sustainability of unregistered farms accounting the majority of all holdings in the country. In this article we employ a holistic framework and assesses sustainability of unregistered agricultural holdings in Bulgaria. Initially method of the study outlined. After that an assessment is made of integral, governance, economic, social, environmental sustainability of unregistered agricultural farms in general and of different size, production specialization, ecological and geographical location as well as on their comparative sustainability in relations to other type of farms in the country. Finally, directions for further research and amelioration of sustainability assessment practices are suggested.
\end{abstract}

Keywords: unregistered farms, sustainability, governance, economic, social, environmental aspects

\section{Introduction}

The issue of adequate assessment of diverse aspects of sustainability of farms of different type is among the most topical academic and practical matters (Andreoli and Tellarini, 2000; Bachev, 2005, 2010, 2016; Bachev and Petters, 2005; Bastianoni et al., 2001; Brklacich. and Smith;Diazabakana et al., 2014; EC, 2001; FAO, 2013; Fuentes, 2004; Häni et al., 2006; OECD, 2001; Rigby et al., 2001; Sauvenier et al., 2005; UN, 2015). Nevertheless, in Bulgaria practically there are no comprehensive studies on sustainability of dominating unregistered holdings (Natural Persons) at current stage of development. The latter account for almost $98 \%$ of all farms in the country, cultivate a third of all farmlands, graze $85 \%$ of cows, $90 \%$ of sheep, and around a third of pigs, and employ almost $93 \%$ of workforce in the sectors (MAF, 2012).

This article applies a holistic framework for assessing sustainability of Bulgarian farms, and evaluates absolute and comparative sustainability of holdings of Natural Persons with different size, product specialization, and ecological and geographical location.

\section{Methodology}

Farm sustainability characterizes the ability (internal potential, incentives, comparative advantages, importance, efficiency) of a particular farm to maintain its governance, economic, social and ecological functions in a long-term in the specific socio-economic and natural environment in which it functions and evolves (Bachev, 2016). Depending on combination of all four dimensions, sustainability of a particular farm could be high, good, unsatisfactory, or farm is unsustainable.

Farm sustainability has for aspects ("pillars"), which are equally important and always have to be taken into account:

- governance sustainability - to have good or high absolute and comparative efficiency in organization and management of activity and (internal and external) relations of the farm, and a high adaptability to evolving socio-economic and natural environment, according to specific preferences (type of enterprise, character of production, long-term goals, etc.) and capabilities (education, experience, available resources, connections, power positions, etc.) of owners of the enterprise;

- economic sustainability - to have good or high productivity of deployed natural, labor, material and financial resources, suf- 
Citation: Hayet L and Ahmed O (2017) Cross-Testing Between Four Varieties: HD 1220 (HIDHAB), ARZ, MAHON X DEMIAS and ANZA OF Constantine Wheat. J AgrAgri Aspect 2017: JAAA-114.

ficient ("acceptable") economic efficiency and competitiveness, and needed financial stability of activity;

- $\quad$ social sustainability - to have good or high social responsibility in regard to farmers, hired labor, other agents, communities, and consumers, and contribute to preservation of agrarian resources and traditions, amelioration of wellbeing and life style of farm households, and development of rural communities and the society as a whole;

- environmental sustainability - to have good or high ecoefficiency of activity, which is to associated with necessary conservation, recovery and improvement of components of natural environment (landscape, lands, waters, biodiversity, atmosphere, climate, ecosystem services, etc.) and the nature as a whole, respecting welfare of farm and wild animals, etc.

This framework for assessing sustainability of Bulgarian farms has to include hierarchical system of 12 Principles, 21 Criteria, 45 Indicators and Reference values. That system let specify the most adequate indicators for the specific Bulgarian conditions taking into account all aspects of farm sustainability. Specific content, justification, modes of selection, calculation and integration of all elements of that framework are presented in details in another publication (Bachev, 2016).

Assessment of sustainability of farms in the country is based on a 2016 survey with the managers of "representative" marketoriented farms of different type. The survey was carried out with assistance of National Agricultural Advisory Service and major agricultural producersassociations, which identified "typical" holdings of different type and location.

Assessment of sustainability level of individual farms is based on first-hand information from the managers of "representative" holdings collected in summer of 2016. The survey with farm managers included 152 of Natural Persons, which comprise around $0,2 \%$ of all Agricultural Producers in Bulgaria (MAF, 2015). The structure and importance of surveyed farms of different kind and location approximately corresponds to the real structure of marketoriented holdings of Natural Persons in the country.

Sustainability of individual farms is based on the estimates of farm managers for each Indicator in four qualitative levels: "High/Higher or Better that the Average in the Sector/Region", "Similar/Good", "Low/Lower or Worse than the Average in the Sector/Region", "Negative/Unsatisfactory/Unacceptable". After that the qualitative estimates have been quantified and transformed into Sustainability Index for each indicator (SI(i)) using following scales: 1 for "High", 0,66 for "Good or Average", 0,33 for "Low", and 0 for "Unsatisfactory or Unacceptable".

Major market-oriented type of farms in the country are Natural Persons, Sole Traders, Cooperatives, and Companies, and comparative sustainability of Natural Persons is evaluated in relations to other juridical type. For classification of farms according to production specialization, ecological and administrative locations the official typology for farming holdings in the country is used. In addition, every manager self-determined his/her farming enterprises as Predominately for Subsistence, rather Small, Middle size or Big for the sector, and located mainly in Plain, Plain-mountainous or Mountainous region. The latter approach guarantees an adequate assessment since farms' managers are well aware of the specificity and comparative characteristics of their holdings in relations to others in the region and (sub)sector.

For integral assessment of sustainability of a farm for each Criterion, Principle, Aspect and Overall level, equal weights are used for each Principle in a particular Aspect, and for each Criterion in a particular Principle, and for each Indicator in a particular Criterion. For interpretation of quantitative levels following sustainability levels of farms are distinguished by a Panel of Experts: "High" - range between 0,84 and 1, "Good" - range between 0,5 to 0,82 , "Low" - range 0,22 to 0,49 , and "Non-sustainable" - between 0 and 0,2. The overall and particular (Aspect, Principle, Criterion, Indicator) sustainability of farms of a specific kind and location is an arithmetic average of the Indexes of individual holdings in that particular group.

\section{Results and Discussion}

Multi-indicators assessment of sustainability level of farms of Natural Persons indicates, that the Integral Sustainability Index is 0,53 , which represents a good level of sustainability of holdings (Figure 1). With the highest levels are Indexes of Environmental $(0,6)$ and Social $(0,55)$ Sustainability of these enterprises, while Index of Governance $(0,51)$ Sustainability is at the border with a low level. What is more, Natural Persons are with a low economic sustainability, which demonstrates that improvement of the latter one is critical for maintaining the overall sustainability of farms of that type. 
Citation: Hayet L and Ahmed O (2017) Cross-Testing Between Four Varieties: HD 1220 (HIDHAB), ARZ, MAHON X DEMIAS and ANZA OF Constantine Wheat. J AgrAgri Aspect 2017: JAAA-114.

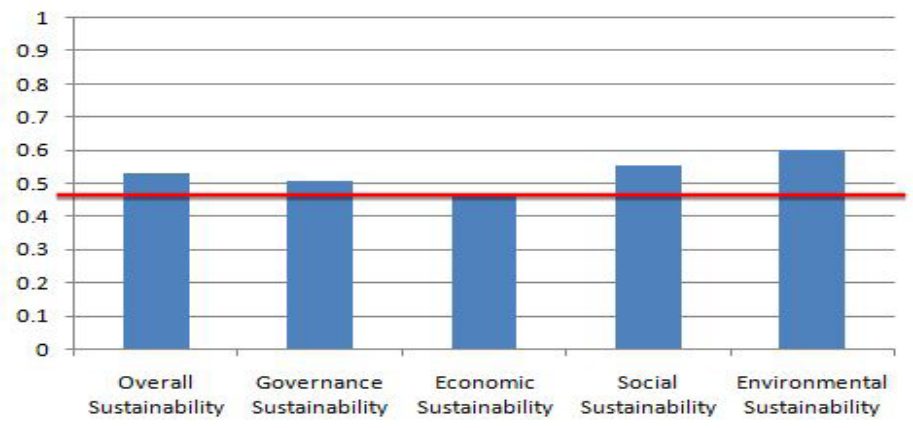

Figure 1: Indexes of Sustainability of Unregistered Agricultural Holdings in Bulgaria

Comparative sustainability of farms of Natural Persons is lower than the average sustainability of farms in the country and levels of other juridical type of enterprises in agriculture (Figure 2). Sustainability level of Natural Persons only approximates the level of Sole Traders and it is much inferior from Companies and Cooperatives. However, while governance and economic sustainability of Natural Persons is lower from all categories of enterprises, in social and environmental aspects it is superior to Sole Traders, and in environmental close to cooperative farms.

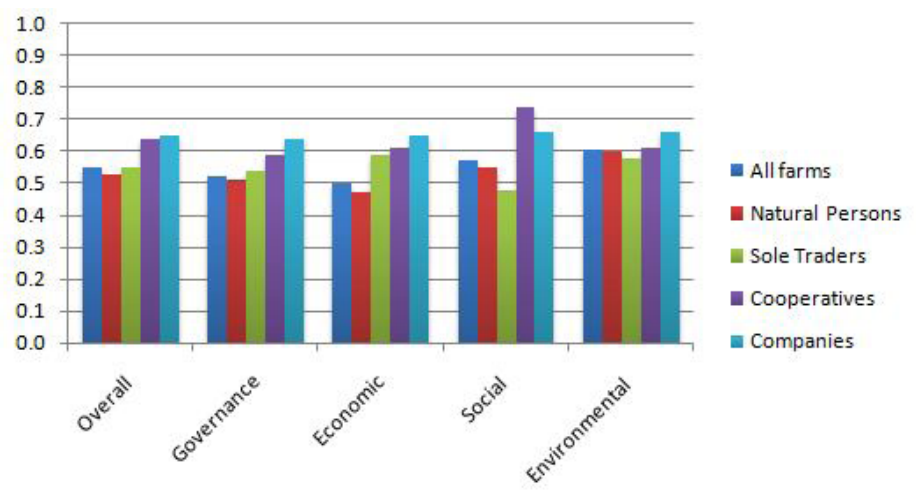

Figure 2: Sustainability of Farms of Different Type in Bulgaria

Analysis of individual Indexes for major sustainability Principles, Criteria and Indicators let identify components contributing to sustainability levels for diverse aspects of sustainability of holdings of Natural Persons. For instance, economic sustainability of farms is low because of the fact that the Index of Financial Stability $(0,47)$ of these enterprises holdings is low (Figure 3$)$. Similarly, the inferior level of the Index of Governance Efficiency $(0,49)$ is responsible for marginal level of governance sustainability of these enterprises. It is also clear that despite that the overall environmental sustainability of holdings is relatively high, the Index of Respecting Animal-Welfare Principle $(0,43)$ is low, and the Index of Preservation of Preservation of Agricultural Lands marginal $(0,52)$. Improvement of the latter two is critical for maintaining the achieved level.

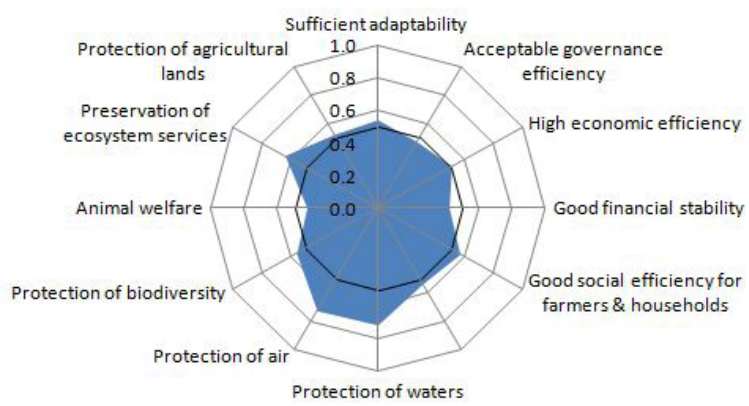

Figure 3: Indexes of Sustainability for Major Principles for Unregistered Agricultural Holdings in Bulgaria

In depth analysis for individual Criteria and Indicators further specifies the elements, which enhance or reduce sustainability level of farms. For instance, insufficient Financial Stability is determined by low Financial Capability $(0,43)$, which is predetermined by unsatisfactory Profitability of Own Capital $(0,36)$, Overall Liquidity $(0,44)$, and Financial Autonomy $(0,48)$ of enterprises (Figure 4 and Figure 5).

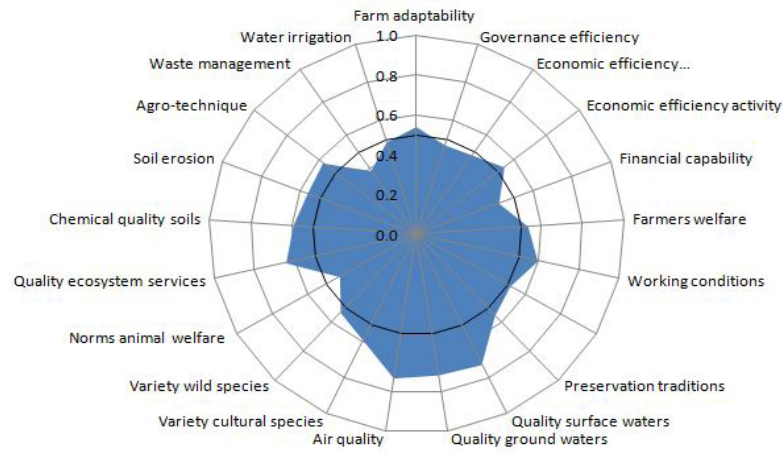

Figure 4: Level of Sustainability for Individual Criteria for Unregistered Agricultural Holdings in Bulgaria

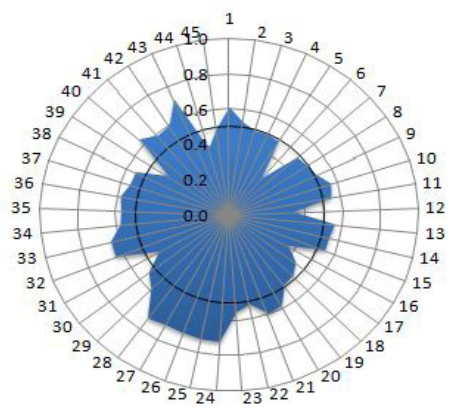

Figure 5. Indicators* of Assessing Sustainability of Unregistered Agricultural Holdings in Bulgaria 
Citation: Hayet L and Ahmed O (2017) Cross-Testing Between Four Varieties: HD 1220 (HIDHAB), ARZ, MAHON X DEMIAS and ANZA OF Constantine Wheat. J AgrAgri Aspect 2017: JAAA-114.

*1-Level of Adaptability to Market Environment; 2-Level of Adaptability to Institutional Environment; 3-Level of Adaptability to Natural Environment; 4-Comparative Efficiency of Supply and Governance of Labor Resources; I5-Comparative Efficiency of Supply and Governance of Natural Recourses; I6-Comparative Efficiency of Supply and Governance of Short-term inputs; I7Comparative Efficiency of Supply and Governance of Long-term Inputs; I8-Comparative Efficiency of Supply and Governance of Innovation; I9-Comparative Efficiency of Supply and Governance of Finance; I10-Comparative Efficiency of Governance of Marketing of Products and Services; I11-Land productivity; I12-Livestock Productivity; I13-Level of Labor productivity; I14-Rate of Profitability of Production; I15-Income of Enterprise; I16-Rate of Profitability of Own Capital; I-17-Overall Liquidity; I18-Financial Autonomy; I19-Income per Farm-household Member; I-20-Satisfaction of Activity; I21-Compliance with Working Conditions Standards; I22-Contribution to Preservation of Rural Communities; I23-Contribution to Preservation of Traditions; I24-Nitrate Content in Surface Waters; I25-Pesticide Content in Surface Waters; I26-Nitrate Content in Ground Waters; I27-Pesticide Content in Ground Waters; I28-Extent of Air Pollution; I-29-Number of Cultural Species; I30-Number of Wild Species; I31-Extent of Respecting Animal Welfare; I32-Extent of Preservation of Quality of Ecosystem Services; I33-Soil Organic Content; I34-Soil Acidity; I35-Soil Soltification; I36-Extent of Wind Erosion; I37-Extent of Water Erosion; I38-Crop Rotation; I39-Number of Livestock per ha of Farmland; I40-Norm of Nitrogen Fertilization; I41-Norm of Phosphorus Fertilization; I42-Norm of Potassium Fertilization; I43-Extent of Application of Good Agricultural Practices; I44Type of Manure Storage; I45-Irrigation Rate

Most sustainability indicators of Natural Persons are low and lead to a decrease in sustainability for individual aspects and the overall level. In governance aspect of sustainability of these holdings are inferior the Level of Adaptability to Natural Environment $(0,49)$, and Comparative Efficiency of Supply and Governance of Labor Resources $(0,49)$, Natural Resources $(0,49)$, Longterm Inputs $(0,49)$, and Innovations $(0,49)$, and extremely low the Comparative Efficiency of Supply and Governance of Short-term Inputs $(0,26)$.

In economics aspect sustainability of Natural Persons is particularly low in respect to Livestock Productivity $(0,34)$, Rate of Profitability of Own Capital $(0,36)$, Overall Liquidity $(0,44)$, and
Financial Autonomy $(0,48)$. In social aspect sustainability of these holdings is only low in relation to Income per Farm-household Member $(0,49)$, while in environmental plan in respect to complying with norms for Number of Livestock per ha of Farmland $(0,43)$, Type of Manure Storage $(0,39)$, Extent of Respecting Animal Welfare $(0,43)$, and Irrigation Rate $(0,49)$. In all these directions adequate measures have to be taken by managers of farms and state authority in order to improve aspect and overall sustainability of Natural Persons.

At the same time, a number of indicators for environmental sustainability of Natural Persons are with relatively high positive positions within a good level: Nitrate and Pesticides Content in Surface and Ground Waters, Extent of Air Pollution, and Extent of Application of Good Agricultural Practices. All these advantages of Natural Persons are to be maintained and enhanced, while other indicators for eco-efficiency increased in order to preserve and increase aspect and overall sustainability of these types of farms.

Low levels of indicators identify the specific areas for improvement of sustainability of farms through adequate changes in management strategy of enterprises and/or public policies for farming structures. For instance, despite that the overall Adaptability of Farms is relatively high $(0,54)$, the Adaptability of Farms to Changes in Natural Environment (climate, extreme events, etc.) is low $(0,49)$. Therefore, effective measures are to be undertaken to improve the latter type of adaptability through education, training, information, amelioration of agro-techniques, structure of production and varieties, technological and organizational innovations, etc.

On the other hand, superior levels of certain indicators show the absolute and comparative advantages of farms of Natural Persons related to sustainable development. At the current stage of development the latter are associated with good eco-efficiency associated with Preservation of Quality of Surface and Ground Waters from contamination with nitrates and pesticides, Preservation of Air Quality and Quality of Eco-system Services, extent of implementation of Good Agricultural Practices, Preservation of Soil Organic Content, application of recommended Norms of Nitrogen Fertilization, good Adaptability to Market (prices, competition, demands, etc.), and Acceptable Working Conditions.

There are significant variations in sustainability of Natural Persons depending on their size, production specialization, and ecological and geographical location (Figure 6). 


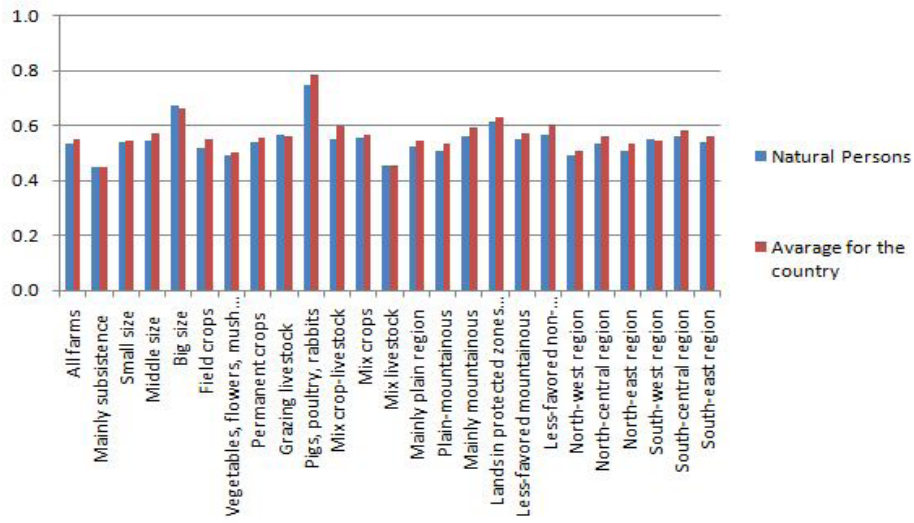

Figure 6: Levels of Sustainability Index of Unregistered Agricultural Holdings Farms of Different Kind and Location in Bulgaria

With the best sustainability, within a good level, are holdings of Natural Persons with Big size, specialized in Pigs, Poultry and Rabbits, these with Lands in Protected Zones and Territories, and located in the South-Central Region of the country. At the same time, with a low sustainability are Natural Persons which are Predominately for Subsistency, those specialized in Mix-Livestock and in Vegetables, Flowers and Mushrooms, and located in the North-West Region of the country. According to the ecological location, the lowest, within a good level, is sustainability of Natural Persons situated in Plain-mountainous Regions of the country.

Holding of Natural Persons are the most numerous and to a great extent they (pre)determine the "average" sustainability level of farms in the country. Consequently, the level of integral sustainability of Natural Persons of different kind deviates insignificantly from the average sustainability levels of respective categories of farms in the country. Simultaneously, considerable variation of sustainability of Natural Persons depending on their kind indicates that the size, product specialization and location of these holdings are more important factors for their sustainability than their juridical status.

The overall and partial sustainability levels of Natural Persons do not give a full picture about the state of all holdings since there is a great variation in the share of farms with different sustainability levels. Almost two-third of farms of Natural Persons in the country are with a good sustainability and only under $1 \%$ with a high sustainability (Figure 7). At the same time, more than a third of all Natural Persons (34\%) are with a low sustainability or unsustainable at all (5\%).

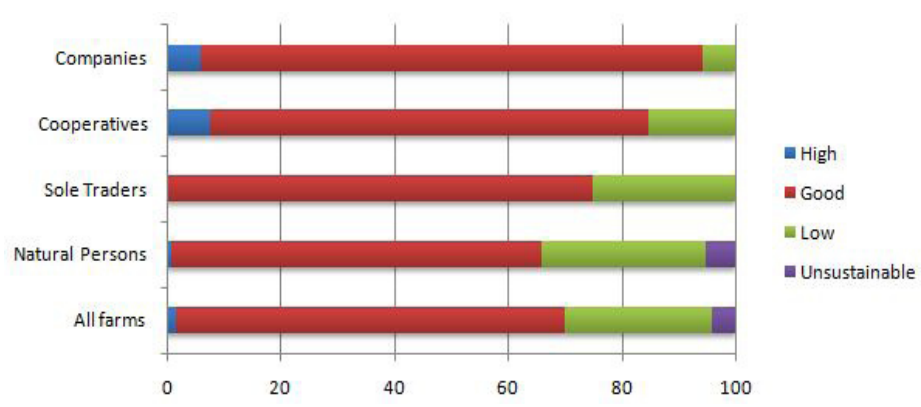

Figure 7: Structure of Farms of Different Type with Unlike Sustainability Level in Bulgarian(percent)

Natural Persons are to a greater extent unsustainable comparing to other categories of farms in the country. The share of Natural Persons with a low sustainability is much bigger of portion of holdings with such level in other juridical types, as unsustainable are inclusively that group of enterprises. The greatest is the share of farms with a good and high sustainability in the group on Companies, followed by Cooperatives and Sole Traders, as every forth of Sole Traders is with a low sustainability level, similarly to $15 \%$ of Cooperatives, and $6 \%$ of Companies.

Above figures demonstrate comparative advantages of other juridical (and governance) type of enterprises comparing with Natural Persons in regard to sustainable development. They confirm well-known trend for constant reduction in number and importance of Natural Persons in the structure of Bulgarian farming enterprises during last two decades (Bachev, 2010).

Analysis of structure of enterprise with different level of sustainability for each sustainability aspect gives important information about the long-term sustainability of Natural Persons and factors for its improvement. Our assessment shows that $45 \%$ of surveyed Natural Persons are with a low governance sustainability or managerially unsustainable. That means that comparative efficiency (potential) for governing supply of labor, land, finance, etc. and marketing of produce is lower than another feasible organization, and that adaptability to evolving environment is insufficient. Furthermore, $48 \%$ of all Natural Persons are with a low economic sustainability or unsustainable at all (each tenth one).

All that means that a considerable part of farms of Natural Persons are with insufficient governance and economic sustainability for meeting contemporary socio-economic, market, institutional and environmental challenges, and they will cease to exists 
Citation: Hayet L and Ahmed O (2017) Cross-Testing Between Four Varieties: HD 1220 (HIDHAB), ARZ, MAHON X DEMIAS and ANZA OF Constantine Wheat. J AgrAgri Aspect 2017: JAAA-114.

in near future unless adequate measures are undertaken (modernization, reorganization, public support, regulations, etc.) for their improving sustainability.

The portion of Natural Persons with inferior economic and governance sustainability is higher than Cooperatives and Companies, and in regard to economic sustainability exceeds Sole Traders as well. Thus, in near future management of resources of (a great portion of) economically and managerially low sustainable and unsustainable holdings of Natural Persons most likely will be transferred to organizations with higher comparative advantages (efficiency, sustainability) of another juridical type and/or Natural Persons with higher sustainability.

As far as the social aspect of sustainability is concerned, the structure is more favorable and the majority of farms of Natural Persons surveyed farms with a good or high social sustainability. Despite that, more than a quarter of holdings are with a low social sustainability or socially unsustainable. Only share of Sole Traders with inferior levels of social sustainability is bigger. That demonstrates that social efficiency of holdings of Natural Persons for farmers, communities and society and a whole do not correspond to contemporary requirements and standards.A good portion of these farms currently are with a low social sustainability or socially unsustainable, which compromises their overall middle and long-term sustainability. Therefore, effective measures have to be undertaken immediately to improve income, labor and living conditions of farmers and farm households as well as their importance for preservation of rural communities and traditions.

Environmental sustainability of the majority of farms of Natural Persons is good or superior, while a considerable portion is with a low sustainability (18\%) or even environmentally unsustainable (5\%). The share of these farms with inferior eco-efficiency is similar to those for Cooperatives and Companies, and gives a way only to Sole Traders. Nevertheless, above figures show, that eco-efficiency in a large number of Natural Persons in the country do not meet contemporary norms and standards for preservation of agricultural lands, waters, air, biodiversity, ecosystem services, and animal welfare. A good number of Bulgarian farms are with a low eco-sustainability or environmentally unsustainable, which also compromises their overall long-term sustainability. Therefore, effective measures have to be undertaken to improve eco-efficiency in these groups through training, informing, stimulation, sanctions, etc.

There is also a significant differentiation in the share of farms with different level of sustainability for the major type of Natural Persons (Figure 8). All Natural Persons with Big size for the sector and specialized in Pigs, Poultry and Rabbits, and most of these in Mix Cops and Permanent Crops, and located in Non- mountainous Regions with Natural Handicaps and with Lands in Protected Zones and Territories are with a good (and a part with a high) sustainability.

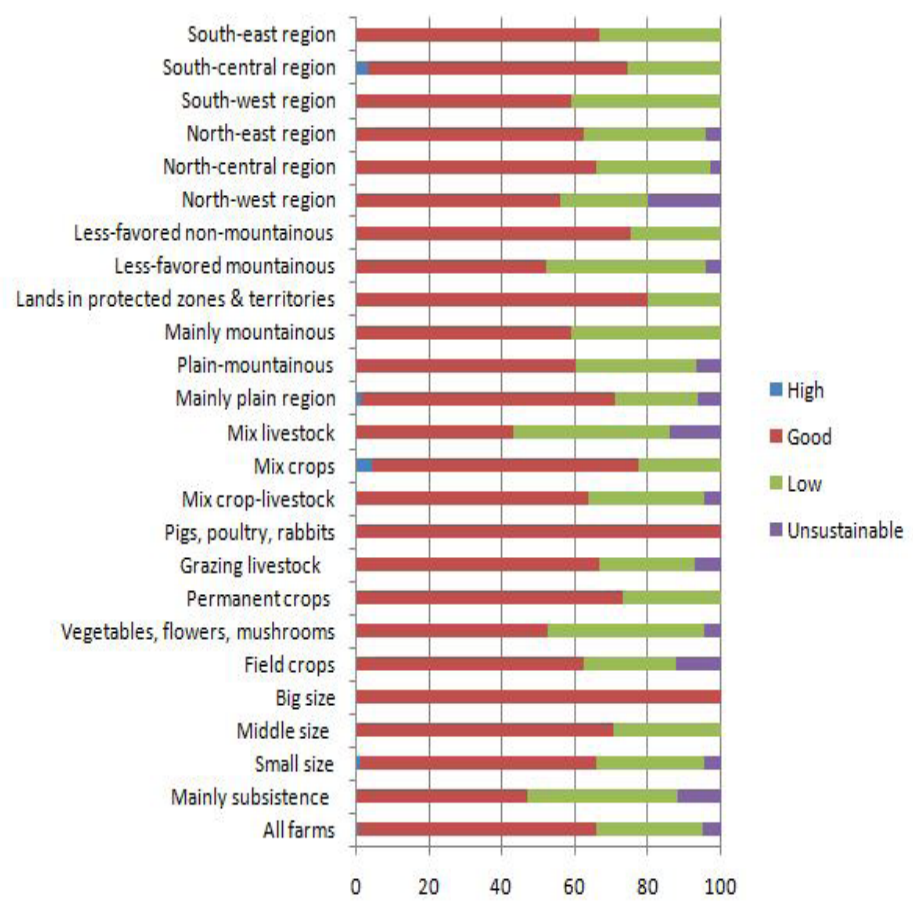

Figure 8: Structure of Unregistered Agricultural Holdings of Different Kind with Unlike Sustainability Level in Bulgaria (percent)

On the other hand, majority of Natural Persons, which are Predominately for Subsistence and these with Mix Livestock are with low sustainability or unsustainable. The portion is also considerable of low sustainable or unsustainable Natural Persons in groups with Vegetables, Flowers and Mushrooms, Grazing Livestock, and Crop-Livestock specialization, those located in Mountainous Regions with Natural Handicaps, in Plain-Mountainous Regions, and in North-West and South-Wets Regions of the country.

Data for dispersion of farming enterprises of different type in groups with diverse level of sustainability has to be taken into account when forecast the number and importance of holdings of Natural Persons of each kind and location, as well as when modernize public (structural, sectorial, regional, environmental, etc.) policies for supporting agricultural producers of certain type, subsectors, eco-systems, and regions of the country.

\section{Conclusion}

Suggested holistic framework gives a possibility to assess, analyze and improve sustainability level of individual farms and 
Citation: Hayet L and Ahmed O (2017) Cross-Testing Between Four Varieties: HD 1220 (HIDHAB), ARZ, MAHON X DEMIAS and ANZA OF Constantine Wheat. J AgrAgri Aspect 2017: JAAA-114.

enterprises of different type in general and for major aspects, principles, criteria and indicators of sustainability. Moreover, different degree of aggregation allows assessment results to be effectively used at various decision-making levels - from lowest (individual or group of enterprises) to the highest (policy making). That approach has to be further discussed, experimented, improved and adapted to the specific conditions of operation and development of farming enterprises of different type and location, as well as special needs of decision-makers at various levels.

The overall sustainability of Natural Persons in the country is at a good level, with superior levels for environmental and social sustainability, close to the border with low level governance sustainability, and inferior economic sustainability. Furthermore, comparative sustainability of these holdings as a whole and for individual aspect is lower than the average sustainability of enterprises in the country and from the level of other juridical (governing) type. There are also great variations in sustainability levels of farms of different kind and location. Besides, the share of Natural Persons with good and high sustainability is much smaller than other categories of enterprises. All that means that majority of Natural Persons do not have comparative advantages in relations to efficiency and sustainability, and in a middle term will cease to exist transferring management of resources into more-efficient and sustainable structures.

Having in mind the importance of such comprehensive assessments of levels and factors of sustainability of farms, and enormous benefits for farm management and agrarian policies, such studies are to be expended and their precision and representation increased. The latter require a close cooperation between all interests parties and participation of farmers, agrarian organizations, local and state authorities, interest groups, research institutes and experts, etc. Moreover, precision of estimates has to be improved and besides on assessments of managers to incorporate relevant information from field tests and surveys, statistical and other data, and expertise of professionals in the area.

\section{References}

1. AndreoliM and Tellarini $V(2000)$ Farm sustainability evaluation: methodology and practice, Agriculture, Ecosystems \& Environment. 77: 43-52.

2. Bachev H (2004) Efficiency of Agrarian Organizations. Farm Management and Rural Planning, 5: 135-150.

3. Bachev H (2005) Assessment of Sustainability of Bulgarian Farms. Proceedings, XIth Congress of the European Association of Agricultural Economists. Copenhagen: EAAE.

4. Bachev H (2010) Governance of Agrarian Sustainability. New York: Nova Science Publishers.

5. Bachev H (2013) Risk Management in Agri-food Sector. Contemporary Economics 7: 45-62.
6. Bachev H (2016) A Framework for Assessing Sustainability of Farming Enterprises. Journal of Applied Economic Sciences 11: 24-43.

7. Bachev, H. (2017). Sustainability Level of Bulgarian Farms. Bulgarian Journal of Agricultural Science 1.

8. Bachev $\mathrm{H}$ and Petters A(2005) Framework for Assessing Sustainability of Farms, in Farm Management and Rural Planning No 6, Kyushu University, Fukuoka 221-239.

9. Bachev H and Tsuji M (2001) Structures for Organization of Transactions in Bulgarian Agriculture. Journal of the Faculty of Agriculture of Kyushu University 46: 123-151.

10. Bachev H and Nanseki T (2008) Environmental Management in Bulgarian Agriculture - Risks, Modes, Major Challenges. Journal of the Faculty of Agriculture of Kyushu University53: 363-373.

11. Bastianoni S, Marchettini N,PanzieriM,TiezziE(2001)Sustainability assessment of a farm in the Chianti area (Italy), Journal of Cleaner Production 9: 365-373.

12. Brklacich M, Bryant C, Smith B (1991)Review and appraisal of concept of sustainable food production systems. Environmental Management 15: 1-14.

13. Diazabakana A, Latruffe L, Bockstaller C, Desjeux $\mathrm{Y}$, Finn $\mathrm{J}$ et al. (2014) A Review of Farm Level Indictors of Ssustainability with a Focus on CAP and FADN, FLINT.

14. EC (2001) A Framework for Indicators for the Economic and Social Dimensions of Sustainable Agriculture and Rural Development. Brussels: European Commission.

15. FAO (2013) SAFA. Sustainability Assessment of Food and Agriculture systems indicators. Rome: FAO.

16. Fuentes M (2004) Farms Management Indicators Related to the Policy Dimension in the European Union, OECD Expert Meeting on Farm Management Indicators and the Environment, 8-12 March 2004, New Zealand.

17. Häni F, Pintér L, Herren H (2006) Sustainable Agriculture. From Common Principles to Common Practice, Proceedings of the first Symposium of the International Forum on Assessing Sustainability in Agriculture (INFASA), March 16, 2006, Bern, Switzerland.

18. Hayati D, Ranjbar Z, Karami E (2010) Measuring Agricultural Sustainability, in E. Lichtfouse (Ed.), Biodiversity, Biofuels, Agroforestry and Conservation Agriculture, Sustainable Agriculture Reviews 5. Springer Science, 73-100.

19. MAF (2012) Agrarian paper. Sofia:Ministry of Agriculture and Food.

20. OECD (2001) Environmental indicators for agriculture. Volume 3: Methods and Results. Paris: OECD.

21. Rigby D, Woodhouse P, Young T, Burton M (2001) Constructing a farm level indicator of sustainable agricultural practice. Ecological Economics 39: 463-478.

22. Sauvenier X, Valekx J, Van CauwenberghN, Wauters E, Bachev $\mathrm{H}$ et al. (2005) Framework for Assessing Sustainability Levels in Belgium Agricultural Systems - SAFE. Brussels: Belgium Science Policy.

23. UN (2015) Paris Climate Change Conference, November-December 2015.

24. Williamson O (1996) The Mechanisms of Governance. New York: Oxford University Press. 